\title{
DOSAGEM DOS NÍVEIS DE PEROXIDAÇÃO LIPÍDICA PELO MÉTODO DE TBARS NA LEVEDURA Saccharomyces cerevisiae MUTANTES AO GENE SIR SUBMETIDAS AO TRATAMENTO COM FICOCIANINA
}

\author{
C. SILVEIRA ${ }^{1}$, F. BENETTI ${ }^{2}$, B. SEGUENKA ${ }^{2}$, G. NICOLETTI ${ }^{1}$, W. F. MARTINS ${ }^{1}$, A. \\ C. V. SALLA ${ }^{2}$, F. N. MELO ${ }^{3}$ e T. E. BERTOLIN ${ }^{2}$ \\ ${ }^{1}$ Universidade Federal de Santa Catarina, Departamento de Engenharia Química e \\ Engenharia de Alimentos \\ ${ }^{2}$ Universidade de Passo Fundo, Faculdade de Engenharia, Curso de Engenharia de \\ Alimentos \\ ${ }^{3}$ Universidade Federal da Paraíba, Centro de Tecnologia \\ E-mail para contato: cam_silveira@hotmail.com
}

RESUMO - O processo de peroxidação lipídica é iniciado pela reação de um radical livre (RL) com ácidos graxos insaturados, presentes nas membranas celulares e nas lipoproteínas. Estudos com antioxidantes têm evidenciado benefícios destes na peroxidação lipídica. Em vista disso, objetivou-se verificar o efeito protetor da ficocianina na lipoperoxidação na levedura Saccharomyces cerevisiae mutantes ao gene Sir. As cepas da levedura Saccharomyces cerevisiae utilizadas foram controle e deletadas aos genes Sir. As células foram crescidas em meio YPD $2 \%$. As cepas foram submetidas a $24 \mathrm{~h}$ de envelhecimento e coletadas para avaliação dos níveis de lipoperoxidação nos tempos $0 \mathrm{~h}$ e $24 \mathrm{~h}$. A análise da lipoperoxidação foi realizada pelo método TBARS (substâncias reativas ao ácido tiobarbitúrico). O tratamento com ficocianina atenuou a lipoperoxidação em todas as cepas, com destaque para cepa deletada ao gene Sir 3, corraborando para uma possível ação protetora da ficocianina.

\section{INTRODUÇÃO}

Um dos principais mecanismos de lesão causada pelo estresse oxidativo é a oxidação da camada lipídica da membrana celular, a lipoperoxidação (LPO). Este processo provoca alterações estruturais e funcionais da membrana, como principalmente a sua perda de integridade, permeabilidade e fluidez, podendo levar à morte celular (Sampaio e Moraes, 2010).

Os lipídios quando oxidados possuem alta capacidade de gerar RL, uma vez que a peroxidação lipídica é a reação do oxigênio molecular com lipídios insaturados. Esta reação de oxidação ocorre devido a fatores ambientais ou pela ação enzimática - pela catalisação de enzimas lipoxigenases ou pelos RL formados nos processos metabólicos (Araújo, 2004).

A partir disso, ocorrem alterações nas membranas celulares, alterando a permeabilidade, resultando na perda da seletividade na troca iônica e liberação do conteúdo de organelas, como as enzimas hidrolíticas dos lisossomas, e formação de produtos citotóxicos, como o malondialdeído (MDA), culminando com a morte celular (Lehninger; Nelson e Cox, 2002). A lipoperoxidação também pode estar associada aos 
mecanismos de envelhecimento, de câncer e à exacerbação da toxicidade de xenobióticos (Ferreira e Matsubara, 1997).

Os produtos resultantes da peroxidação lipídica são parâmetros importantes para o monitoramento do dano causado por ERO em lipídeos (Vasconcelos et al., 2007). Esses são instáveis e se degradam em vários produtos secundários como o MDA. Os níveis de MDA são largamente utilizados como marcadores da peroxidação lipídica nos estados de estresse oxidativo (Yildirim et al., 2007)

O processo de reparo das lesões está relacionado com a remoção de danos da molécula de DNA e a reconstituição das membranas celulares danificadas. Os estudos com antioxidantes têm evidenciado benefícios no uso de nutrientes isolados no tratamento e prevenção de doenças relacionadas ao envelhecimento. Estes são agentes responsáveis pela inibição e redução das lesões causadas pelos radicais livres nas células dificultando o ataque das espécies reativas sobre os lipídeos. No entanto, o efeito deletério do deste processo varia de um organismo para outro, de acordo com a idade, estado fisiológico e a dieta (Bertolin et al., 2009).

$\mathrm{Na}$ atualidade, o interesse pelo desenvolvimento de terapias antienvelhecimento vem crescendo exponencialmente, contudo muitas contribuições nessa linha de pesquisa ainda se fazem necessárias. Percebe-se a partir de estudos já existentes, que a dieta sobrestrição calórica contribui com a longevidade, em razão da menor geração de EROs. A dieta sob RC tem sido relatada por diversos autores, contribuindo com a diminuição do processo do envelhecimento. $\mathrm{O}$ uso de compostos naturais e suplementos alimentares também têm sido alvo de muitos estudos com relatos de que estes agem de forma benéfica em muitos sistemas biológicos (Bescos et al., 2008).

A ficocianina é principal pigmento da cianobactéria Spirulina platensis. O interesse em recursos biológicos, em especial as algas, como fontes de substâncias antioxidantes vem crescendo de maneira significativa. Os estudos mostram que as algas como peptídeos de polissacarídeos e ficobiliproteínas podem afetar a multiplicação de tumores (Liu et al., 2000).

Ambrosi et al. (2011) mostraram que a microalga pode ser utilizada como alimento pelo homem devido a sua composição química, que apresenta elevada quantidade e quantidade de aminoácidos essenciais, minerais, ácidos graxos poliinsaturados e vitaminas. Possui grande quantidade de compostos fenólicos, tocoferol e pigmentos como carotenóides, ficocianina e clorofila (Ambrosi et al., 2011).

A cianobactéria apresenta características que sugerem aplicações clínicas, conferindo efeitos terapêuticos em pacientes acometidos de diversas patologias. Estudos clínicos e epidemiológicos estabeleceram uma relação inversa entre a ingestão de compostos antioxidantes e a incidência de doenças crônicas degenerativas, epidemiológicas, como as cardiovasculares além de apresentar-se como estimulante ao sistema imunológico (Andrews et al., 2010).

Os compostos extraídos de microalgas como a Spirulina platensis são reconhecidos mundialmente devido ao deu uso na alimentação humana e como alimentos funcional e nutracêutico (Bertolin et al., 2009). 
As sirtuínas compreendem um grupo de proteínas desacetilizadoras dependentes da coenzima NAD (Nicotinamida Adenina Dinucleotídeo), envolvidas no controle do metabolismo energético e associadas à longevidade. Além das histonas, um crescente número de proteínas tem sido identificado como alvo das sirtuínas, entre eles estão proteínas estruturais e diversos fatores de transcrição (Gallinari, et al. 2007).

Enquanto cada sirtuína é um produto de um gene específico, a expressão destes genes e a atividade das enzimas nos tecidos são fortemente afetadas por mudanças no ambiente como dieta e estilo de vida. Alguns fatores reportados por influenciarem na expressão destes genes incluem: RC, exercício, álcool, fumo, exposição ao frio, estresse oxidativo, administração de compostos como resveratrol, quercetina e melatonina (Gallinari, et al. 2007).

Com o exposto acima, objetivou-se verificar o efeito protetor da ficocianina na lipoperoxidação na levedura Saccharomyces cerevisiae mutantes ao gene Sir.

\section{MATERIAL E MÉTODOS}

\subsection{Antioxidante}

O composto antioxidante analisado foi a ficocianina (FC) principal pigmento da microalga Spirulina platensis.

\subsection{Modelo experimental}

A levedura Saccharomyces cerevisiae deletada ao gene $\operatorname{sir} 1 \Delta, \operatorname{sir} 2 \Delta, \operatorname{sir} 3 \Delta$ e sir $4 \Delta$ e controle foram obtidas da Euroscarf, Frankfurt, Germany. O Quadro 1 apresenta as linhagens que serão utilizadas nos experimentos.

As linhagens de levedura Saccharomyces cerevisiae foram mantidas em meio YPD sob refrigeração a $4{ }^{\circ} \mathrm{C}$, como apresentado no Quadro 1 . A manutenção dos microorganismos foi realizada através de repiques periódicos em meio YPD. No caso das cepas mutantes $\operatorname{sir} 1 \Delta$, $\operatorname{sir} 2 \Delta$, $\operatorname{sir} 3 \Delta$ e $\operatorname{sir} 4 \Delta$, o meio de cultura será acrescido de $0,02 \%$ de geneticina. As culturas serão mantidas a $4^{\circ} \mathrm{C}$ em ágar inclinado (cultura estoque).

\subsection{Condições de cultivo}

As células, retiradas de um repique fresco em meio sólido YPD $2 \%$, foram cultivadas em erlenmeyers, contendo $20 \%$ do seu volume preenchido por meio YPD 2 $\%$. Após a realização do inóculo, as culturas foram incubadas a $28{ }^{\circ} \mathrm{C}$ em agitador orbital ajustado para $160 \mathrm{rpm}$ até a primeira fase exponencial de crescimento (entre 0,5 e $0,9 \mathrm{mg}$ de peso seco de células $/ \mathrm{mL}$ ). Nesta fase, as células crescidas em YPD $2 \%$ apresentam um metabolismo fermentativo, utilizando a glicose presente no meio como única fonte de carbono e não dependendo do oxigênio como aceptor final dos elétrons.

\subsection{Oxidação de lipídios pelo método de TBARS}

Inicialmente foram recolhidas por centrifugação cerca de $50 \mathrm{mg}$ de células antes e após 1 e $24 \mathrm{~h}$ de exposição a $0,8 \mathrm{mg} / \mathrm{mL}$ de ficocianina. As células foram lavadas duas vezes com água destilada gelada, ressuspensas em $500 \mu \mathrm{L}$ de TCA 10\% (ácido tri-cloro acético) e transferidas para tubo de parede grossa. Foram adicionadas $1,5 \mathrm{~g}$ de pérolas de 
vidro e as células rompidas sob agitação vigorosa com 6 ciclos de 20 s no vortex e 20 s no gelo.

$\mathrm{O}$ extrato foi recolhido em micro tubo e as pérolas de vidro lavadas com $500 \mu \mathrm{de}$ TCA 10\%, sendo recolhidos no mesmo eppendorf. Após a lise os extratos foram centrifugação a $4000 \mathrm{rpm}$, sendo o sobrenadante coletado e utilizado para as análises de peroxidação lipídica através do método TBARS (substâncias reativas ao ácido tiobarbitúrico).

O ensaio foi realizado conforme a Tabela 1.

Tabela 1: Composição das soluções para utilização na metodologia TBARS

\begin{tabular}{cccc}
\hline & Branco & $\begin{array}{c}\text { Amostra } 1 \\
(\mathrm{~mL})\end{array}$ & $\begin{array}{c}\text { Amostra 2 } \\
(\mathrm{mL})\end{array}$ \\
\hline Água destilada & 0,3 & 0,15 & - \\
EDTA 0,1 M & 0,1 & 0,1 & 0,1 \\
Extrato & - & 0,15 & 0,15 \\
Ac. Tiobarbitúrico & 0,6 & 0,6 & 0,6 \\
$1 \%$ em NaOH 0,05M & & 1 & 1 \\
Volume total & 1 & 1 & \\
\hline
\end{tabular}

A mistura reacional foi incubada a $100^{\circ} \mathrm{C}$ por 15 minutos. Os tubos foram resfriados e a absorbância medida espectrofotometricamente a 532nm.

A dosagem foi determinada de acordo com Steels, Learmonth e Watson (1994).

\section{RESULTADOS E DISCUSSÃO}

A oxidação de lipídeos foi verificada através do método TBARS, obtida antes e após o envelhecimento de $24 \mathrm{~h}$. A Tabela 2 apresenta a média \pm desvio padrão de dois experimentos independentes.

Tabela 2 - Valores médios de peroxidação lipídica (pmoles MDA/mg de cel.) para os diferentes tratamentos na Saccharomyces cerevisiae

\begin{tabular}{ccc}
\hline Tratamentos & \multicolumn{2}{c}{ 2\% glicose } \\
\cline { 2 - 3 } & $\mathbf{0 h}$ & $\mathbf{2 4 h}$ \\
\hline Controle & $167,24 \pm 40,08$ & $314,56 \pm 56,46$ \\
Controle $+\mathrm{FC} *$ & & $196,72 \pm 11,49$ \\
sirl & $255,66 \pm 41,06$ & $377,54 \pm 209,15$ \\
sirl $+\mathrm{FC} *$ & & $338,16 \pm 122,13$ \\
sir2 & $197,46 \pm 66,48$ & $483,90 \pm 114,8$ \\
sir2 $+\mathrm{FC} *$ & $137,61 \pm 51,55$ & $354,65 \pm 40,56$ \\
sir 3 & & $551,12 \pm 111,25$ \\
sir3 $+\mathrm{FC} *$ & $178,36 \pm 95,24$ & $390,22 \pm 202,47$ \\
sir4 & & $388,11 \pm 287,03$ \\
sir4 + FC* & & $253,81 \pm 40,23$ \\
\hline$*$ cepas submetidas a 1 1h de cultivo em presença da ficocianina.
\end{tabular}


Com o intuito de verificar o aumento de peroxidação lipídica devido ao processo de envelhecimento cronológico, os resultados foram expressos como a razão entre o nível de peroxidação lipídica após 24 h de envelhecimento e antes do envelhecimento (0 h) em todas as cepas.

Podemos perceber que as cepas deletadas aos genes $\operatorname{sir}(\operatorname{sir} 1, \operatorname{sir} 2, \operatorname{sir} 3$ e $\operatorname{sir} 4$ ), apresentaram maiores parâmetros de peroxidação lipídica quando comparadas à cepa controle, com exceção da cepa deletada ao gene sir1, que mostrou parâmetros de peroxidação lipídica inferiores em relação à cepa controle.

Quando tratadas com ficocianina $(\mathrm{P}+\mathrm{FC})$, todas as cepas apresentaram maiores valores de peroxidação lipídica em relação à cepa controle, com destaque para a cepa deletada ao gene sir3. Este resultado não apresentou diferenças significativas. Comparando cada cepa de forma individual, nossos resultados mostraram que, quando submetidas ao tratamento com ficocianina, as cepas de leveduras Saccharomyces cerevisiae deletadas aos genes $\operatorname{sir}(\operatorname{sir} 1, \operatorname{sir} 2, \operatorname{sir} 3$ e $\operatorname{sir} 4)$ e controle, apresentaram níveis de peroxidação lipídica inferiores, em relação às cepas ausentes de ficocianina.

Romay, Ramirez e González (2001), investigaram a atividade antioxidante da ficocianina frente à peroxidação lipídica microssomal, utilizando microssomas de fígado de ratas. No estudo foi observado que a ficocianina mostrou ser mais entre 6 e 7 vezes mais eficiente que outros dois antioxidantes (ácido ascórbico e trolox). Ao final do estudo, os autores consideraram que a ficocianina reúne os requisitos para transformarse em um candidato a fármaco.

O estudo de Bescos et al., (2008), realizado em neuroblastomas humanos, demonstra que a ficocianina é um potente eliminador de radicais hidroxila e peróxidos, tendo a capacidade de inibição da peroxidação lipídica.

Os resultados da pesquisa de Khan et al. (2005) sugeriram a prevenção do aumento do MDA no tecido cardíaco em camundongos tratados com Spirulina, quando a cardiotoxicidade era induzida pela Doxorrubicina, um fármaco amplamente utilizado no tratamento de cânceres. Ainda, os níveis séricos de MDA foram reduzidos em ratos jovens tratados com Spirulina no estudo de Sharma, Sharma, Sharma (2005). Outros autores verificaram que indivíduos jovens que receberam Spirulina diminuíram a peroxidação lipídica em análise sanguínea (Lu et al, 2006).

\section{CONCLUSÃO}

O uso da terapia com ficocianina mostrou benefício na peroxidação lipídica analisada no modelo levedura Saccharomyces cerevisiae.

\section{REFERÊNCIAS}

AMBROSI, M. A.; REINEHR, C. O., BERTOLIN, T. E., COSTA, J. A. V., COLLA, L. M. Propriedades de saúde da Spirulina spp. Revista de Ciências Farmacêuticas Básica e Aplicada, v. 29, n. 2, 2008. 
ANDREWS, S. R., SAHU, N. P., AK, P., MUKHERJEE, S. C., KUMAR, S. Yeast extract, brewer's yeast and spirulina in diets for Labeo rohita fingerlings affect haematoimmunological responses and survival following Aeromonas hydrophila challenge. Research in Veterinary Science, v. 91, n. 1, p. 103-109, 2011.

ARAÚJO, J. M .A. Química de alimentos: teoria e prática. $3^{\mathrm{a}}$ ed. Viçosa: UFV, 2004.

BERTOlin, T. E., PILATTI, D., BAVARESCO, K., GIACOMINI, A.C., COLlA, L. M., COSTA, J. A. V. Effect of microalga Spirulina platensis (Arthrospira platensis) on hippocampus lipoperoxidation and lipid profile in rats with induced hypercholesterolemia. Brazilian Archives of Biology and Technology, v. 52, p. 12531259, 2009.

BESCÓS, P. B., ESTRADA, E. P., FRESNO, A. M. V. NEUROPROTECTION BY SPIRULINA PLATENSIS PROTEAN EXTRACT AND PHYCOCYANIN AGAINST IRON-INDUCED TOXICITY IN SH-SY5Y NEUROBLASTOMA CELLS. TOXICOLOGY IN VITRO, V. 22, N. 6, P. 1496-1502, 2008.

FERREIRA, A. L. A., MATSUBARA, L. S., Radicais livres: conceitos, doenças relacionadas, sistema de defesa e estresse oxidativo. Revista da Associação Médica Brasileira, v. 43, n. 1, p. 61-68, 1997.

GALLINARI P., DI MARCO S., JONES P., PALLAORO M., STEINKÜHLER C. HDACs, histone deacetylation and gene transcription: from molecular biology to cancer therapeutics. Cell Res,v. 17, p. 195-211, 2007.

LEHNINGER, A. L., NELSON, D. L., COX, M. Princípios de Bioquímica. 3 ed. São Paulo: Sarvier, 2002.

LIU, Y., XU, L., CHENG, N., LIN, L., ZHANG, C. Inhibitory effect of phycocyanin from Spirulina platensis on the growth of human leukemia K562 cells. Journal of Applied Phycology, v. 12, p. 125-130, 2000.

LU, H. K., HSIEH C._C., HSU J.J., YANG Y.K., CHOU H. N. Preventive effects of Spirulina platensis on skeletal muscle damage under exercise-induced oxidative stress. European Journal of Applied Physiology, v. 98, n. 2, p. 220-226, 2006.

ROMAY, L. C.; REMIREZ. D; GONZÁLEZ, R. L. Actividad antioxidante de la ficocianina frente a radicales peroxílicos y la peroxidación lipídica microsomal. Revista Cubana de Investigaciones Biomédicas, v. 20, n.1, p. 38-41, 2001.

SAMPAIO, R. C.; MORAES, C. Estresse oxidativo e envelhecimento: papel do exercício físico. Motriz, v. 16, n. 2, p. 506- 515, 2010.

SHARMA, S., SHARMA, S., SHARMA, K. P. Protective role of Spirulina feed in a freshwater fish (Poecilia reticulata Peters) exposed to an azo dye-methyl red. Indian Journal of Experimental Biology, v. 43, n. 12, p. 1165-1169, 2005.

STEELS, E. L., LEARMONTH, R. P., WATSON, K. Stress tolerance and membrane lipid insaturation in Saccharomyces cerevisiae grown aerobically or anaerobically. Microbiology. 140:569-76, 1994. 
VASCONCELOS, S., M., L., GOULART, M., O. F., MOURA, J. B. F., MANFREDINI, V., BENFATO, M. S., KUBOTA, L. T. Espécies reativas de oxigênio e de nitrogênio, antioxidantes e marcadores de dano oxidativo em sangue humano: principais métodos analíticos para sua determinação. Química Nova, v. 30, n. 5, p. 1323-1338, 2007.

YILDIRIM, A., KOTAN, D., YILDIRIN, S., AYGUL, R., AKÇAY, F. Increased lipid peroxidation and decreased antioxidant response in serum and cerebrospinal fluid in acute ischemic stroke. Turkey Journal Medicine Science. v. 37, n. 2, 2007. 